\title{
Inverse association between maternal 250HD level and cord GLP-1/GIP concentrations
}

\author{
Shimpei Niwa ${ }^{1,2}$, Hidetoshi Mezawa ${ }^{1,3}$, Naoaki Kobayashi ${ }^{3,4}$, Hiroyuki Ida $^{3}$ and Mitsuyoshi Urashima ${ }^{1,3}$
}

BACKGROUND: Because vitamin D may have beneficial effects on glucose metabolism in pregnant women with gestational diabetes mellitus, we explored whether maternal 25-hydroxyvitamin D (25OHD) levels in normal pregnancy have association with diabetes-related hormone levels and glycated albumin (GA).

METHODS: A prospective cohort study was performed to collect serum samples from 612 pairs of pregnant women and cord blood of their offspring. Levels of $25 \mathrm{OHD}$ and GA in maternal and cord blood were measured by radioimmunoassay and enzyme assay, respectively. Using cord serum, 12 diabetes-related hormones were assayed. Spearman's rank correlation coefficient was used to quantify the strength of association between biomarkers.

RESULTS: A prominent association between maternal and cord 250HD levels ( $r=0.76,95 \%$ confidence intervals (Cls): $0.73-0.79, P<0.0001)$ and weak association between maternal and cord GA ( $r=0.22,95 \%$ Cls: $0.14-0.30, P<0.0001)$ were shown. Among the 12 diabetes-related hormones, both maternal and cord 25OHD levels showed prominent negative associations with glucagon-like peptide 1 (GLP-1) and glucose-dependent insulinotropic polypeptide (GIP).

CONCLUSIONS: These results suggest that decreased maternal 25OHD may be associated with decreased cord 25OHD and increased cord GLP-1 and GIP levels, which may be involved with the transfer of maternal glucose to the fetus.

\section{INTRODUCTION}

Vitamin D is made primarily under the skin by exposure to sunlight and can be obtained to a lesser extent in foods such as mushrooms, oily fish, and egg yolks. Vitamin D is first hydroxylated in the liver to form 25-hydroxyvitamin D (25OHD), then a very small amount of $25 \mathrm{OHD}$ is activated in the kidney to play important roles in the body, including in bone integrity and calcium metabolism (1). Indeed, vitamin D supplementation with calcium can prevent bone fracture and bone loss in the elderly (2). In addition to calcium metabolism, vitamin D repletion for $12 \mathrm{wk}$ not only increases serum vitamin $\mathrm{D}$ concentrations but also improves $\beta$-cell activity (3).
Moreover, maternal vitamin D deficiency during pregnancy has been suggested to be associated with an increased risk of gestational diabetes mellitus $(4,5)$. In fact, recent randomized, double-blind, placebo-controlled clinical trials have suggested that vitamin $\mathrm{D}$ supplementation can decrease fasting glucose as well as insulin levels in gestational diabetes $(6,7)$, although the results have been inconsistent (8). In addition, associations between serum $25 \mathrm{OHD}$ and glucose levels in pregnant women without gestational diabetes remain unknown. Therefore, using a Bio-Plex MAGPIX Suspension Array System (Bio-Rad, Hercules, CA), we performed screening of cord blood for 12 well-known diabetes-related hormones: glucagon-like peptide 1 (GLP-1); glucose-dependent insulinotropic polypeptide (GIP); ghrelin; insulin; c-peptide; glucagon; leptin; plasminogen activator inhibitor-1 (PAI-1); resistin; visfatin; adipsin; and adiponectin. We then analyzed associations between levels of these hormones and 25OHD and glycated albumin (GA), an independent marker of anemia sometimes observed in pregnant women in maternal and cord blood (9).

\section{RESULTS}

\section{Participant Characteristics}

Among the 650 pregnant women who fulfilled inclusion criteria, a total of 612 mother/infant pairs participated in this study. Maternal characteristics and lifestyles divided by three 25OHD levels of mothers (deficient, insufficient, and sufficient) are shown in Table 1. More than half of the participants were $25 \mathrm{OHD}$ deficient. Participants with lower 25OHD levels tended to spend less time engaged in outdoor activities, to have fewer siblings, and to show lower GA levels than those with higher 25OHD levels. However, no significant differences in maternal and neonatal anthropometric measures, other maternal lifestyles including smoking, alcohol consumption, and dietary habits, or neonatal complications at birth were identified.

\section{Maternal and Cord Blood 250HD Levels \\ Levels of 25OHD in cord blood showed strong positive asso- ciations with those in maternal blood at 34 gestational weeks}

\footnotetext{
'Division of Molecular Epidemiology, Jikei University School of Medicine, Tokyo, Japan; ${ }^{2}$ Safety and Risk Management Department, Daiichi Sankyo Co., Ltd., Tokyo, Japan; ${ }^{3}$ Department of Pediatrics, Jikei University School of Medicine, Tokyo, Japan; ${ }^{4}$ Department of Pediatrics, Shiomidai Hospital, Yokohama, Japan. Correspondence: Mitsuyoshi Urashima (urashima@jikei.ac.jp)

Received 29 April 2015; accepted 14 September 2015; advance online publication 30 December 2015. doi:10.1038/pr.2015.253
} 
Table 1. Maternal and offspring characteristics stratified by maternal 25OHD levels

\begin{tabular}{|c|c|c|c|c|c|}
\hline \multirow[b]{2}{*}{ Variables $^{\mathrm{a}}$} & \multicolumn{5}{|c|}{ Maternal 25OHD } \\
\hline & $\begin{array}{c}\text { Total, } \\
n=612\end{array}$ & $\begin{array}{c}\text { Deficient } \\
(0 \leq<20 \mathrm{ng} / \mathrm{ml}) \\
n=337\end{array}$ & $\begin{array}{c}\text { Insufficient } \\
(20 \leq<30 \mathrm{ng} / \mathrm{ml}) \\
n=181\end{array}$ & $\begin{array}{c}\text { Sufficient } \\
\begin{array}{c}(30 \leq<80 \mathrm{ng} / \mathrm{ml}) \\
n=94\end{array}\end{array}$ & $P$ \\
\hline Maternal age, years (SD) & $31.5(5.0)$ & $31.2(5.2)$ & $31.7(4.7)$ & $31.9(4.9)$ & $0.34^{d}$ \\
\hline Maternal body mass index ${ }^{\mathrm{b}}, \mathrm{kg} / \mathrm{m}^{2}$ (SD) & $21.0(2.9)$ & $21.1(3.0)$ & $20.9(2.8)$ & $21.0(3.0)$ & $0.83^{d}$ \\
\hline Vitamin D supplementation ${ }^{c}, n(\%)$ & $46(7.8)$ & $18(5.7)$ & $18(10.3)$ & $10(21.7)$ & $0.074^{e}$ \\
\hline Time spent on outdoor activity & & & & & $<0.001^{* e}$ \\
\hline Almost none, $n(\%)$ & $43(7.4)$ & $31(9.8)$ & $8(4.7)$ & $4(4.4)$ & \\
\hline Average $<0.5 \mathrm{~h} / \mathrm{d}, n(\%)$ & $116(20.0)$ & $72(22.6)$ & $37(21.5)$ & $7(7.7)$ & \\
\hline Average $0.5-1.0 \mathrm{~h} / \mathrm{d}, n(\%)$ & $178(30.6)$ & $99(31.1)$ & $61(35.5)$ & $18(19.8)$ & \\
\hline Average $1.0-2.0 \mathrm{~h} / \mathrm{d}, n(\%)$ & $162(27.9)$ & $77(24.2)$ & $45(26.2)$ & $40(44.0)$ & \\
\hline Average $>2.0 \mathrm{~h} / \mathrm{d}, n(\%)$ & $82(14.1)$ & $39(12.3)$ & $21(12.2)$ & $22(24.2)$ & \\
\hline Number of siblings, $0 / 1 / 2 / 3 / \geq 4, n$ & $268 / 223 / 93 / 20 / 8$ & $170 / 105 / 46 / 9 / 7$ & 73/71/29/7/1 & $25 / 47 / 18 / 4 / 0$ & $0.015^{* e}$ \\
\hline Glycated albumin, \% (SD) & $13.9(1.4)$ & $13.7(1.3)$ & $14.1(1.5)$ & $14.2(1.2)$ & $0.0001^{* f}$ \\
\hline Gestational age, weeks (SD) & $38.8(1.2)$ & $38.9(1.3)$ & $38.9(1.1)$ & $38.7(1.3)$ & $0.52^{f}$ \\
\hline Male gender, $n(\%)$ & $314(51)$ & $181(54)$ & $90(50)$ & $43(46)$ & $0.35^{\mathrm{e}}$ \\
\hline \multicolumn{6}{|l|}{ Anthropometry at birth } \\
\hline Birth weight, g (SD) & $3,065(396)$ & $3,080(419)$ & $3,047(353)$ & $3,043(393)$ & $0.56^{d}$ \\
\hline Birth height, cm (SD) & $48.7(1.9)$ & $48.8(2.0)$ & $48.8(1.7)$ & $48.6(1.9)$ & $0.89^{f}$ \\
\hline Birth head circumference, cm (SD) & $33.2(1.4)$ & $33.3(1.4)$ & $33.2(1.3)$ & $33.1(1.5)$ & $0.50^{f}$ \\
\hline Birth chest circumference, cm (SD) & $31.9(1.7)$ & $31.9(1.7)$ & $31.9(1.6)$ & $31.9(1.6)$ & $0.99^{f}$ \\
\hline Kaup index, $\mathrm{g} / \mathrm{cm}^{2}(\mathrm{SD})$ & $12.9(1.1)$ & $12.9(1.1)$ & $12.8(1.0)$ & $12.8(1.1)$ & $0.72^{f}$ \\
\hline \multicolumn{6}{|l|}{ Apgar score } \\
\hline At 1 min, mean (SD) & $8.6(0.7)$ & $8.5(0.8)$ & $8.6(0.7)$ & $8.5(0.7)$ & $0.53^{f}$ \\
\hline At 5 min, mean (SD) & $9.2(0.6)$ & $9.1(0.6)$ & $9.2(0.5)$ & $9.2(0.5)$ & $0.65^{f}$ \\
\hline \multicolumn{6}{|l|}{ Complications at birth } \\
\hline Neonatal jaundice, $n$ (\%) & $33(5.4)$ & $19(5.6)$ & $12(6.6)$ & $2(2.1)$ & $0.28^{\mathrm{e}}$ \\
\hline Transient tachypnea of newborn, $n$ (\%) & $24(3.9)$ & $18(5.3)$ & $4(2.2)$ & $2(2.1)$ & $0.13^{\mathrm{e}}$ \\
\hline
\end{tabular}

(Spearman's rank correlation coefficient: $0.76,95 \%$ confidence intervals (CIs): $0.73-0.79, P<0.0001$ ). Median 25OHD level in cord blood was $10 \mathrm{ng} / \mathrm{ml}$, approximately half the mean of $19 \mathrm{ng} / \mathrm{ml}$ in maternal serum (Figure 1 ).

\section{Maternal and Cord Blood GA Levels}

Median (25th-75th percentile) GA was 9.8\% (range: 9.2$10.3 \%$ ) in cord blood and $13.7 \%$ (range: $13.0-14.6 \%$ ) in maternal blood. Normal range of GA in healthy adults according to SRL data is considered to be between 12.4 and $16.3 \%$. Sixty-five (11\%) and $30(5 \%)$ pregnant women were below and above this normal range, respectively. In contrast, all GA values in cord blood except one case were below the lower limit of the normal range in healthy adults. Levels of GA in cord blood were positively associated with GA in maternal blood at 34 gestational weeks (Spearman's rank correlation coefficient: 0.22, 95\% CIs: 0.14-0.30, $P<0.0001$; Figure 2).

\section{Associations Between 250HD and GA Levels}

Levels of 25OHD in maternal blood were positively associated with GA in maternal blood at 34 gestational weeks (Spearman's rank correlation coefficient: 0.21 , 95\% CIs: 0.13-0.29, $P<0.0001$; Figure 3). On the other hand, no significant associations were seen between cord 25OHD and cord GA, between cord 25OHD and maternal GA, or between maternal 25OHD and cord GA.

\section{Associations Between 12 Kinds of Diabetes-Related Hormones and 250HD in Either Cord Blood or Maternal Blood}

Compared with levels in healthy adults for the 12 kinds of hormones measured with the same Bio-Plex suspension array system, mean GLP-1 level was $~ 100$-fold higher, ghrelin, glucagon, visfatin, and adiponectin were $\sim 10$-fold higher, adipsin, PAI-1, and resistin were several times higher, and GIP was a couple of times higher. In contrast, c-peptide, insulin, and 


\section{Articles $\mid$ Niwa et al.}

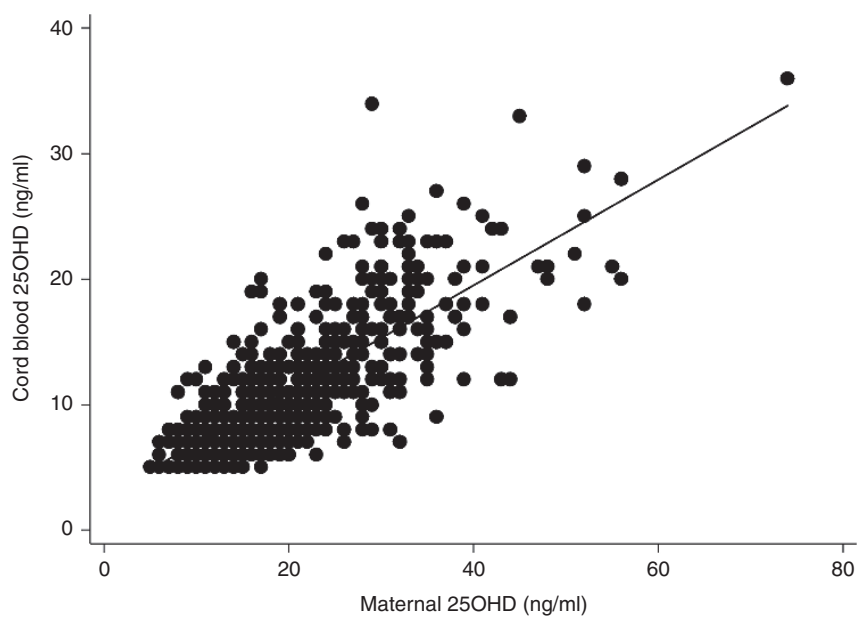

Figure 1. Association between maternal and cord blood 25OHD levels. We used linear regression models to assess the association between maternal and cord blood 250HD levels. Spearman's rank correlation coefficient was used to quantify the strength of the association. 25OHD, 25-hydroxyvitamin D.

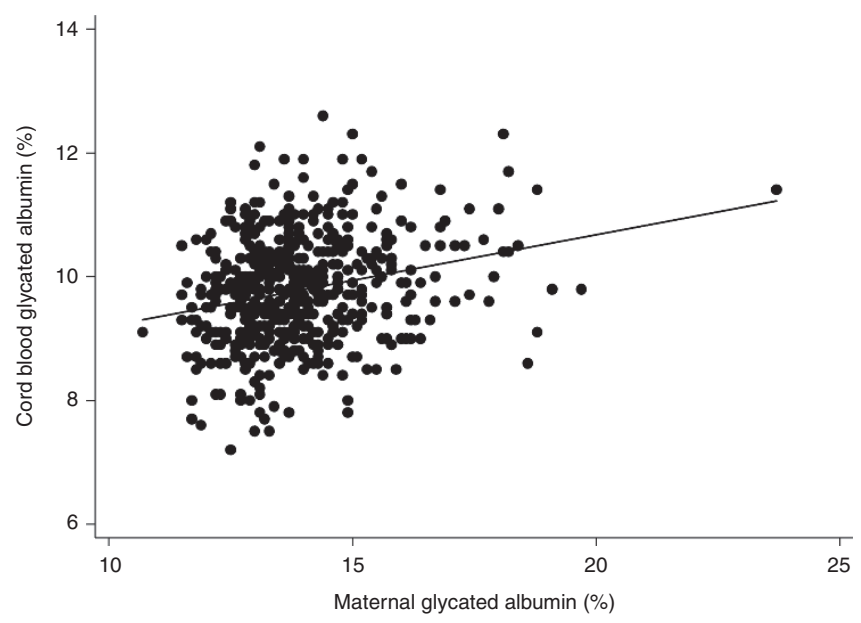

Figure 2. Association between maternal and cord blood glycated albumin levels. We used linear regression models to assess the association between maternal and cord blood glycated albumin levels. Spearman's rank correlation coefficient was used to quantify the strength of the association.

leptin did not differ markedly from those in healthy adults (10). Among these 12 kinds of hormones, both GLP-1 and GIP were prominently and negatively associated with 25OHD in both cord blood and maternal blood in both mono and multiple variant analyses (Tables 2 and 3 ). No other hormones showed significant associations with both cord and maternal blood.

\section{Associations Between the 12 Diabetes-Related Hormones or GA} in Cord Blood, Maternal Blood, or Cord-Maternal GA Ratio

Among the 12 kinds of diabetes-related hormones, associations of GA either in cord blood or in maternal blood as well as cord-maternal GA ratio (calculated as cord GA divided by maternal GA (\%)) were analyzed by Spearman's rank correlation coefficient (Table 4 ) and multiple linear regression

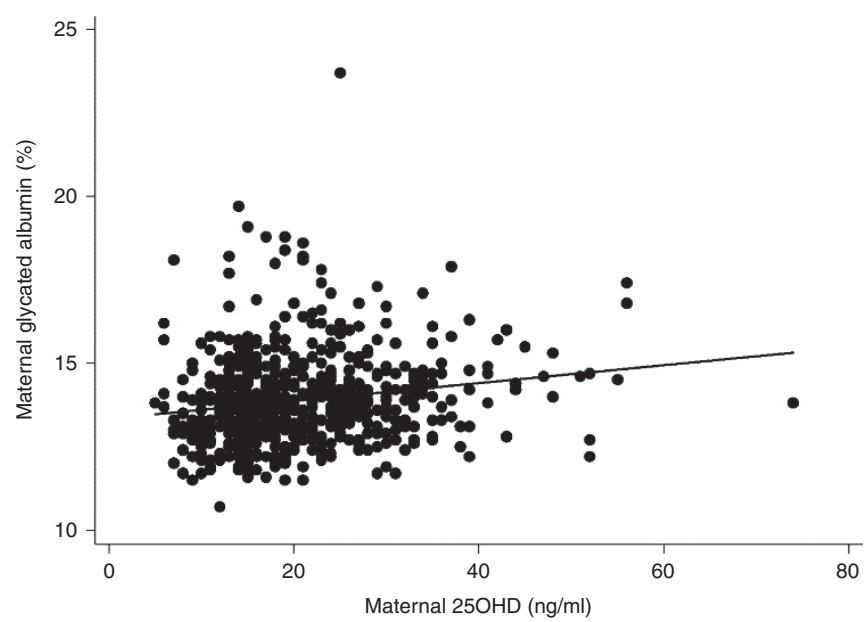

Figure 3. Association between maternal $25 \mathrm{OHD}$ and glycated albumin levels. We used linear regression models to assess the association between maternal 25OHD and glycated albumin levels. Spearman's rank correlation coefficient was used to quantify the strength of the association. 25OHD, 25-hydroxyvitamin D.

(Table 5). Insulin, c-peptide, GIP, and ghrelin levels were positively associated and resistin, visfatin, and adipsin were negatively associated with GA in cord blood. In contrast to GA in cord blood, GIP and GLP-1 were negatively associated with GA in maternal blood. As we were interested in this conversion of negative and positive correlations, we created cordmaternal GA ratio as a new parameter. Cord-maternal GA ratio showed a weak positive association with GIP $(r=0.22)$, GLP-1 $(r=0.22)$, and ghrelin $(r=0.18)(P<0.0001$ each $)$.

\section{DISCUSSION}

Using the Bio-Plex suspension array system, we conducted a prospective cohort study to screen 12 kinds of diabetes-related hormones for associations with cord and maternal 25OHD, as well as GA. To the best of our knowledge, this study is the first to find that GLP-1 and GIP are associated with 25OHD and GA.

First, we demonstrated a strong linear relationship between serum levels of maternal and cord 250HD ( $r=0.76,95 \%$ CIs: $0.73-0.79, P<0.0001)$, supporting previous findings (11-14). $25 \mathrm{OHD}$ was reported to be transferred from mother to fetus across the placenta (15-18). Our result also suggests that 25OHD may be passively transferred from mother to fetus through the placenta. We also found a positive association between GA levels of maternal and cord blood, as in a previous study (19), but the association was not as strong as that observed between maternal and cord 25OHD. Albumin was reported not to significantly pass through the placenta (20), but fetal liver can synthesize albumin at a high rate at two-thirds of gestation $(21,22)$. These results suggest that glucose may be not only passively, but also actively, transferred from mother to fetus through the placenta through regulation by unknown factors.

Second, we found a positive association between maternal $25 \mathrm{OHD}$ and maternal GA in normal pregnancy. In contrast to our results, most previous studies have focused on pregnant 
Table 2. Hormones associated with $25 \mathrm{OHD}$ in cord blood and maternal blood

\begin{tabular}{|c|c|c|c|c|c|c|}
\hline \multirow[b]{2}{*}{ Measures in cord blood } & \multicolumn{3}{|c|}{ Correlation with $25 \mathrm{OHD}$ in cord blood } & \multicolumn{3}{|c|}{ Correlation with $25 \mathrm{OHD}$ in maternal blood } \\
\hline & $r^{\mathrm{b}}$ & $95 \% \mathrm{Cl}$ & $P^{c}$ & $r^{b}$ & $95 \% \mathrm{Cl}$ & $P^{c}$ \\
\hline Insulin (pg/ml) & -0.10 & $(-0.18,-0.02)$ & 0.011 & -0.06 & $(-0.14,0.02)$ & 0.16 \\
\hline C-peptide (pg/ml) & 0.02 & $(-0.06,0.10)$ & 0.60 & 0.06 & $(-0.02,0.14)$ & 0.16 \\
\hline $\mathrm{GIP}(\mathrm{pg} / \mathrm{ml})$ & -0.21 & $(-0.29,-0.13)$ & $<0.0001^{*}$ & -0.12 & $(-0.20,-0.04)$ & $0.0031^{*}$ \\
\hline $\mathrm{GLP} 1(\mathrm{pg} / \mathrm{ml})$ & -0.35 & $(-0.42,-0.28)$ & $<0.0001^{*}$ & -0.23 & $(-0.30,-0.15)$ & $<0.0001^{*}$ \\
\hline Ghrelin (pg/ml) & -0.10 & $(-0.18,-0.02)$ & 0.015 & -0.08 & $(-0.16,0.00)$ & 0.053 \\
\hline Glucagon (pg/ml) & -0.11 & $(-0.19,-0.03)$ & 0.0062 & -0.04 & $(-0.12,0.04)$ & 0.33 \\
\hline Leptin (pg/ml) & -0.02 & $(-0.10,0.06)$ & 0.60 & -0.05 & $(-0.13,0.04)$ & 0.27 \\
\hline PAl (pg/ml) & 0.02 & $(-0.06,0.10)$ & 0.56 & 0.02 & $(-0.06,0.10)$ & 0.65 \\
\hline Resistin (pg/ml) & 0.03 & $(-0.05,0.16)$ & 0.45 & 0.03 & $(-0.06,0.11)$ & 0.55 \\
\hline Visfatin (pg/ml) & -0.07 & $(-0.15,0.01)$ & 0.10 & -0.06 & $(-0.14,0.02)$ & 0.17 \\
\hline Adipsin (pg/ml) & 0.05 & $(-0.03,0.13)$ & 0.25 & -0.08 & $(-0.16,0.00)$ & 0.05 \\
\hline Adiponectin (pg/ml) & 0.05 & $(-0.04,0.13)$ & 0.26 & -0.07 & $(-0.15,0.01)$ & 0.09 \\
\hline
\end{tabular}

Table 3. Incretins associated with $250 \mathrm{HD}$ in cord blood and maternal blood by multiple linear regression ${ }^{\mathrm{a}}$

\begin{tabular}{|c|c|c|c|c|c|c|c|c|}
\hline \multirow{2}{*}{$\begin{array}{l}\text { Measures in cord } \\
\text { blood }^{b}\end{array}$} & \multicolumn{4}{|c|}{ Correlation with $25 \mathrm{OHD}$ in cord blood } & \multicolumn{4}{|c|}{ Correlation with $25 \mathrm{OHD}$ in maternal blood } \\
\hline & Coefficiency & $t$ & $95 \% \mathrm{Cl}$ & $P$ & Coefficiency & $t$ & $95 \% \mathrm{Cl}$ & $P$ \\
\hline $\mathrm{GIP}(\mathrm{pg} / \mathrm{ml})$ & -0.34 & -4.69 & -0.49 to -0.20 & $<0.0001^{*}$ & -0.20 & -2.58 & -0.35 to -0.05 & $0.01 *$ \\
\hline GLP1 (pg/ml) & -0.49 & -7.15 & -0.62 to -0.35 & $<0.0001^{*}$ & -0.17 & -2.30 & -0.32 to -0.25 & $0.02^{*}$ \\
\hline
\end{tabular}

25OHD, 25-hydroxyvitamin D; Cl, confidence interval; GIP, glucose-dependent insulinotropic polypeptide; GLP, glucagon-like peptide.

aMultivariate analysis was performed by linear regression adjusting for potential confounders such as maternal age, maternal BMI, intake of vitamin D supplement, time spent for outdoor activity, number of sibling, and month of the birth. ${ }^{\circ}$ Data were transformed by natural logarithm. ${ }^{*} P<0.05$.

women with gestational diabetes mellitus (23), type 1 diabetes (24) or type 2 diabetes (25) and have shown negative correlations between 25OHD and glucose control levels. However, these inverse associations between $25 \mathrm{OHD}$ and glucose levels have not been studied in healthy adults or pregnant women without gestational diabetes mellitus, and causal relationships have not always been shown $(25,26)$. For example, obesity can represent a confounder for both $25 \mathrm{OHD}$ and abnormal glucose metabolism (27).

Third, we identified GLP-1 and GIP as significant diabetesrelated hormones associated with 25OHD in both maternal and cord blood among the 12 diabetes-related hormones. To the best of our knowledge, this represents a novel finding. Both GLP-1 and GIP are gut-derived incretin hormones that stimulate insulin and suppress glucagon secretion, inhibit gastric emptying, and reduce appetite and food intake (28). Placental transfer of both incretin hormones might be considered negligible (29), and both hormones are secreted in the fetus (30-33). Eating provokes the secretion of multiple gastrointestinal hormones involved in the regulation of gut motility, secretion of gastric acid and pancreatic enzymes, gall bladder contraction, and nutrient absorption as well as insulin secretion. In contrast to adults, nutrition is basically supplied through the placenta to fetuses, not through eating. Moreover, GLP-1 seems to be higher than in healthy adults using the same Bio-Rad suspension array system $(10,34)$. However, the active form of GLP-1 in cord blood was reported to be close to the lower limit of detection (35). Thus, even the higher levels of GLP-1 and GIP in cord blood observed in this study do not necessary to affect glucose levels decreasing by increasing insulin and decreasing glucagon secretion through the pancreas as observed in adults. The roles and mechanisms of GLP-1 and GIP secretion in the fetus warrant further investigation in the future.

Fourth, maternal GA levels were negatively associated with GLP-1 and GIP $(r=-0.13)$, whereas cord GA levels showed a positive association $(r=0.13)$. Cord-maternal GA ratio was positively associated with GLP-1 $(r=0.22)$, GIP $(r=0.22)$, and ghrelin $(r=0.18)$. These results imply that GLP-1, GIP, and ghrelin may facilitate active transfer of glucose from maternal blood to fetal blood through the placenta.

This study has several limitations. First, the study was designed as a prospective cohort to investigate 25OHD and GA levels in maternal blood at 34 gestational weeks as exposures and diabetes-related hormones in cord blood at birth as outcomes. Although a time gap existed between exposures and outcomes, this study was close in nature to a cross-sectional design. We thus cannot discuss causal relationships between 25OHD and GLP-1/GIP levels or between cord-maternal GA ratio and GIP/GLP-1/ghrelin levels, only the existence of 
Articles | Niwa et al.

Table 4. Hormones associated with GA in cord blood and maternal blood

\begin{tabular}{|c|c|c|c|c|c|c|}
\hline \multirow[b]{2}{*}{ Hormones in cord blood } & \multicolumn{2}{|c|}{$\begin{array}{l}\text { Correlation with GA in } \\
\text { cord blood }\end{array}$} & \multicolumn{2}{|c|}{$\begin{array}{l}\text { Correlation with GA in } \\
\text { maternal blood }\end{array}$} & \multicolumn{2}{|c|}{$\begin{array}{c}\text { Correlation with } \\
\text { cord-maternal GA ratio }\end{array}$} \\
\hline & $r^{b}$ & $P^{\mathrm{d}}$ & $r^{b}$ & $P^{d}$ & $r^{b}$ & $P^{d}$ \\
\hline C-peptide (pg/ml) & 0.19 & $<0.0001^{*}$ & 0.05 & 0.19 & 0.09 & 0.03 \\
\hline $\mathrm{GIP}(\mathrm{pg} / \mathrm{ml})$ & 0.13 & $0.0030^{*}$ & -0.13 & $0.0023^{*}$ & 0.22 & $<0.0001^{*}$ \\
\hline Glucagon (pg/ml) & 0.008 & 0.85 & -0.07 & 0.07 & 0.07 & 0.08 \\
\hline Leptin (pg/ml) & -0.02 & 0.66 & 0.04 & 0.28 & -0.08 & 0.05 \\
\hline PAl (pg/ml) & -0.08 & 0.06 & 0.03 & 0.53 & -0.08 & 0.06 \\
\hline Resistin (pg/ml) & -0.18 & $<0.0001^{*}$ & -0.01 & 0.82 & -0.12 & 0.008 \\
\hline
\end{tabular}

GA, glycated albumin; GIP, glucose-dependent insulinotropic polypeptide; GLP, glucagon-like peptide.

aData were transformed by natural logarithm. 'bspearman's rank correlation coefficient was represented by $r$. 'Ratio was simply calculated as GA in cord blood divided by GA in maternal blood. dSince levels of 12 diabetes-related hormones were measured, values of $P<0.004(=0.05 / 12)$ were considered significant. ${ }^{*} P<0.004$.

Table 5. Hormones associated with GA in cord blood and maternal blood by multiple linear regression ${ }^{\mathrm{a}}$

\begin{tabular}{|c|c|c|c|c|c|c|c|c|c|c|c|c|}
\hline \multirow{2}{*}{$\begin{array}{l}\text { Measures in cord } \\
\text { blood }^{\mathrm{b}}\end{array}$} & \multicolumn{4}{|c|}{ Correlation with GA in cord blood } & \multicolumn{4}{|c|}{ Correlation with GA in maternal blood } & \multicolumn{4}{|c|}{ Correlation with cord-maternal GA ratio ${ }^{c}$} \\
\hline & Coefficiency & $\mathrm{t}$ & $95 \% \mathrm{Cl}$ & $P$ & Coefficiency & $\mathrm{t}$ & $95 \% \mathrm{Cl}$ & $P$ & Coefficiency & $\mathrm{t}$ & $95 \% \mathrm{Cl}$ & $P$ \\
\hline Insulin (pg/ml) & 0.03 & 3.26 & $\begin{array}{l}0.01 \\
\text { to } 0.06\end{array}$ & $0.001^{*}$ & 0.02 & 1.53 & $\begin{array}{l}-0.01 \\
\text { to } 0.04\end{array}$ & 0.127 & 0.01 & 1.47 & $\begin{array}{l}-0.002 \\
\text { to } 0.02\end{array}$ & 0.141 \\
\hline C-peptide (pg/ml) & 0.05 & 5.13 & $\begin{array}{l}0.03 \\
\text { to } 0.06\end{array}$ & $<0.0001^{*}$ & 0.01 & 1.39 & $\begin{array}{l}-0.01 \\
\text { to } 0.03\end{array}$ & 0.164 & 0.01 & 2.95 & $\begin{array}{l}0.004 \\
\text { to } 0.02\end{array}$ & $0.003^{*}$ \\
\hline $\mathrm{GIP}(\mathrm{pg} / \mathrm{ml})$ & 0.07 & 3.88 & $\begin{array}{l}0.03 \\
\text { to } 0.10\end{array}$ & $<0.0001^{*}$ & -0.06 & -3.31 & $\begin{array}{l}-0.10 \\
\text { to }-0.03\end{array}$ & $0.001^{*}$ & 0.04 & 5.73 & $\begin{array}{l}0.03 \\
\text { to } 0.06\end{array}$ & $<0.0001^{*}$ \\
\hline Ghrelin (pg/ml) & 0.06 & 4.35 & $\begin{array}{l}0.03 \\
\text { to } 0.08\end{array}$ & $<0.0001^{*}$ & -0.01 & -0.68 & $\begin{array}{l}-0.04 \\
\text { to } 0.02\end{array}$ & 0.496 & 0.03 & 4.37 & $\begin{array}{l}0.01 \\
\text { to } 0.04\end{array}$ & $<0.0001^{*}$ \\
\hline Resistin (pg/ml) & -0.01 & -3.30 & $\begin{array}{l}-0.02 \\
\text { to }-0.01\end{array}$ & $0.001^{*}$ & -0.01 & -1.24 & $\begin{array}{l}-0.02 \\
\text { to } 0.004\end{array}$ & 0.217 & -0.003 & -1.35 & $\begin{array}{l}-0.01 \\
\text { to } 0.001\end{array}$ & 0.178 \\
\hline
\end{tabular}

GA, glycated albumin; GIP, glucose-dependent insulinotropic polypeptide; GLP, glucagon-like peptide.

"Multivariate analysis was performed by linear regression adjusting for potential confounders such as maternal age, maternal BMI, intake of vitamin D supplement, time spent for outdoor activity, number of sibling, and month of the birth. 'Data were transformed by natural logarithm. 'Ratio was simply calculated as GA in cord blood divided by GA in maternal blood. ${ }^{*} P<0.05$.

significant associations. Second, we applied the BioPlex assay for simultaneous quantification of multiple analytics, in a process termed multiplexing. However, this technique is not considered optimal for measuring levels of gut hormones (36). With other methods, levels of some of these hormones might differ markedly $(10,34)$. We therefore compared diabetesrelated hormone levels as measured by BioPlex within samples of this study population, and not with results from other studies. Third, we compared hormone levels in cord blood with those in healthy adults as provided by Bio-Rad Laboratories. However, the number of samples used for their data was only 10 or $11(10,34)$. We can therefore make only a rough estimate of whether hormone levels seem higher in cord blood than in adults.

In conclusion, among the 12 diabetes-related hormones, both cord and maternal 25OHD levels showed prominent negative associations with GLP-1 and GIP. Moreover, GLP-1, GIP, and ghrelin showed positive associations with cord-maternal GA ratio.

\section{METHODS}

\section{Study Design}

This prospective cohort study was conducted at Shiomidai Hospital in Kanagawa prefecture, a general hospital in a rural area of Japan located at 35 degrees $24 \mathrm{~min}$ north latitude, and 139 degrees $36 \mathrm{~min}$ east longitude. Inclusion criteria were pregnant women $\geq 20 \mathrm{y}$ old 
at entry and independent of vitamin D supplement intake. Exclusion criteria were pregnant women who: (i) showed major complications such as gestational diabetes mellitus or toxemia of pregnancy; (ii) needed emergent caesarean section; (iii) showed multiple fetuses such as twins; (iv) had a fetus with clear evidence of intrauterine growth retardation or congenital malformation; (v) did not have samples available; and (vi) had other difficulties judged by the obstetrician or pediatrician in charge. Enrollment was performed by the collaborating pediatrician (N.K.). Pregnant women were enrolled from June 2011 to September 2012.

\section{Ethics Statement}

The study protocol was developed by all authors and approved by the ethics committee at Jikei University School of Medicine and the clinical study committee at Jikei Hospital, as well as the institutional review board at Shiomidai Hospital. The data monitoring center was in the Division of Epidemiology at Jikei University School of Medicine, and all data were monitored and fixed by H.M., who did not participate in statistical analyses. All women provided written, informed consent to participate in the study.

\section{Questionnaires About Lifestyle}

During the third trimester of pregnancy, participants were asked to send back questionnaires containing: (i) basic data such as age, weight before pregnancy and recent weight, and height for pregnant women, along with age, weight, and height for husband (or partner); (ii) smoking status (current, past, or nonsmoker), and exposure to passive smoking; (iii) mean frequency, amount, and kind of alcohol consumption per week over the preceding month of pregnancy; (iv) mean frequency of consumed food items (dried shiitake, mushroom, salmon, sardines, mackerel, saury, tuna, egg) per week during the preceding month of pregnancy; (v) vitamin D supplementation, and timing and dosage if used; (vi) mean daily exposure to sunlight; (vii) family structure; (viii) medical history of allergic diseases (bronchial asthma, atopic dermatitis, food allergy, drug allergy, metal allergy, solar eczema, allergic rhinitis, chemical sensitivity, and others); (ix) skin reaction to sun exposure as evaluated with a modified Fitzpatrick scale (type 1 = always burns, never tans; type 2 = usually burns, tans minimally; type 3 = sometimes mild burn, tans uniformly; or type $4=$ rarely burns, always tans well); and (x) number of siblings.

\section{Clinical Information at Birth}

The following clinical information were collected: (i) planned cesarean section or not; (ii) birth date; (iii) weight, height, head circumference, and chest circumference at birth; (iv) Apgar score at 1 and $5 \mathrm{~min}$; and (v) complications such as neonatal jaundice and transient tachypnea of the newborn.

\section{Samples and 250HD Measurements}

Serum samples from participating pregnant women were collected at $34 \mathrm{wk}$ of gestation. Umbilical cord blood $(5-10 \mathrm{ml})$ was sampled from the placenta side after placental delivery at birth. Soon after blood sampling without freezing, levels of 25OHD were measured by radioimmunoassay at SRL (Hachioji, Tokyo, Japan) (37), which has participated in the Laboratory Accreditation Program of College of American Pathologist. Minimal detection level was $5 \mathrm{ng} / \mathrm{ml}$. The Institute of Medicine has defined adequate vitamin $\mathrm{D}$ status as a serum $25 \mathrm{OHD}$ level $\geq 20 \mathrm{ng} / \mathrm{ml}$ for the general population, including pregnant women (38). When levels are $\geq 30 \mathrm{ng} / \mathrm{ml}$, bone fracture can be prevented (39). We therefore divided participating pregnant women into three groups according to 25OHD levels: deficient, $<20 \mathrm{ng} / \mathrm{ml}$; insufficient, $\geq 20 \mathrm{but}<30 \mathrm{ng} / \mathrm{ml}$; and sufficient, $\geq 30 \mathrm{ng} / \mathrm{ml}$.

\section{Multiplex Immunoassay Analysis}

After freezing at $-80{ }^{\circ} \mathrm{C}$, a series of hormones related to metabolism (GLP-1, GIP, ghrelin, insulin, c-peptide, glucagon, leptin, PAI1 , resistin, visfatin, adipsin, and adiponectin) were assayed in cord blood using the Bio-Plex MAGPIX Suspension Array System (BioRad, Hercules, CA), according to the instructions from the manufacturer. A single operator blinded to clinical information performed all measurements using human diabetes assay kits. Identical positive and negative quality controls are included on each assay in duplicate. Assays were performed in one batch, with samples mixed randomly.
The lower limit of detection ranged from $2.4 \mathrm{pg} / \mathrm{ml}$ for resistin to 310 $\mathrm{pg} / \mathrm{ml}$ for visfatin, while intra-assay variability was less than $10 \%$. Mean recovery ratio represented by observed data/expected data was $99.4 \%$.

\section{Glycated Albumin}

After a maximum of $2.5 \mathrm{y}$ freezing at $-80^{\circ} \mathrm{C}$, serum samples obtained from participating pregnant women and cord blood of offspring were measured for GA using an enzymatic method by SRL (40).

\section{Statistical Analysis}

Continuous data were compared among the three maternal groups by means of ANOVA for factors showing normal distribution and by Kruskal-Wallis equality-of-populations rank test for factors not showing normal distribution. The $\chi^{2}$ test was used for analysis of binary or categorical data. Spearman's rank correlation coefficient was used to quantify the strength of association between 25OHD/GA and diabetes-related hormones not showing normal distributions. All reported $P$ values were two-sided. Values of $P<0.05$ were considered significant in the analyses of participant characteristics. On the other hand, since 12 diabetes-related hormones were measured, values of $P<0.00417(=0.05 / 12)$ were considered significant using Spearman's rank correlation. Linear regression model was applied to obtain a coefficiency. For significant variables in Spearman's rank correlation analysis, multivariate analysis was performed by linear regression adjusting for potential confounders such as maternal age, maternal BMI, intake of vitamin D supplement, time spent for outdoor activity, number of sibling, and month of the birth. All statistical analyses were independently performed by M.U. and S.N., who were not involved in data collection. Stata version 13.1 software (StataCorp, College Station, TX) was used for all analyses.

\section{ACKNOWLEDGMENTS}

We thank the patients who provided blood samples for this research project. We are also grateful to Chikako Sakanashi for technical support with BioPlex.

\section{STATEMENT OF FINANCIAL SUPPORT}

This work was supported by the Ministry of Education, Culture, Sports, Science and Technology in the Japan-Supported Program for the Strategic Research Foundation at Private Universities and the Jikei University School of Medicine.

Disclosure: The authors declare that they have no competing interest.

\section{REFERENCES}

1. Holick MF. Vitamin D deficiency. N Engl J Med 2007;357:266-81.

2. Tang BM, Eslick GD, Nowson C, Smith C, Bensoussan A. Use of calcium or calcium in combination with vitamin $\mathrm{D}$ supplementation to prevent fractures and bone loss in people aged 50 years and older: a meta-analysis. Lancet 2007;370:657-66.

3. Al-Sofiani ME, Jammah A, Racz M, et al. Effect of vitamin D supplementation on glucose control and inflammatory response in type II diabetes: a double blind, randomized clinical trial. Int J Endocrinol Metab 2015; 13:e22604.

4. Zhang C, Qiu C, Hu FB, et al. Maternal plasma 25-hydroxyvitamin D concentrations and the risk for gestational diabetes mellitus. PLoS One 2008;3:e3753.

5. Burris HH, Camargo CA Jr. Vitamin D and gestational diabetes mellitus. Curr Diab Rep 2014;14:451.

6. Asemi Z, Karamali M, Esmaillzadeh A. Effects of calcium-vitamin D cosupplementation on glycaemic control, inflammation and oxidative stress in gestational diabetes: a randomised placebo-controlled trial. Diabetologia 2014;57:1798-806.

7. Asemi Z, Hashemi T, Karamali M, Samimi M, Esmaillzadeh A. Effects of vitamin D supplementation on glucose metabolism, lipid concentrations, inflammation, and oxidative stress in gestational diabetes: a double-blind randomized controlled clinical trial. Am J Clin Nutr 2013;98:1425-32.

8. Yap C, Cheung NW, Gunton JE, et al. Vitamin D supplementation and the effects on glucose metabolism during pregnancy: a randomized controlled trial. Diabetes Care 2014;37:1837-44. 


\section{Articles $\mid$ Niwa et al.}

9. Hiramatsu Y, Shimizu I, Omori Y, Nakabayashi M; JGA (Japan Glycated Albumin) Study Group. Determination of reference intervals of glycated albumin and hemoglobin Alc in healthy pregnant Japanese women and analysis of their time courses and influencing factors during pregnancy. Endocr J 2012;59:145-51.

10. Wang Q-S ZH, Yeung D, Ma L, Geng W. Development and validation of multiplex assays for human diabetes biomarkers, 2010. (http://www.biorad.com/webroot/web/pdf/lsr/literature/Bulletin_5985A.pdf.)

11. Við Streym S, Kristine Moller U, Rejnmark L, Heickendorff L, Mosekilde L, Vestergaard P. Maternal and infant vitamin D status during the first 9 months of infant life-a cohort study. Eur J Clin Nutr 2013;67:1022-8.

12. Molla AM, Al Badawi M, Hammoud MS, et al. Vitamin D status of mothers and their neonates in Kuwait. Pediatr Int 2005;47:649-52.

13. Weisman Y, Occhipinti M, Knox G, Reiter E, Root A. Concentrations of 24,25-dihydroxyvitamin D and 25-hydroxyvitamin D in paired maternalcord sera. Am J Obstet Gynecol 1978;130:704-7.

14. Bouillon R, Van Baelen H, De Moor P. 25-hydroxyvitamin D and its binding protein in maternal and cord serum. J Clin Endocrinol Metab 1977;45:679-84.

15. Bruns ME, Bruns DE. Vitamin D metabolism and function during pregnancy and the neonatal period. Ann Clin Lab Sci 1983;13:521-30.

16. Ron M, Levitz M, Chuba J, Dancis J. Transfer of 25-hydroxyvitamin D3 and 1,25-dihydroxyvitamin D3 across the perfused human placenta. Am J Obstet Gynecol 1984;148:370-4.

17. Hoogenboezem T, Degenhart HJ, de Muinck Keizer-Schrama SM, et al. Vitamin D metabolism in breast-fed infants and their mothers. Pediatr Res 1989;25:623-8.

18. Food and Nutrition Board, National Academy of Sciences. Nutrition During Pregnancy. Washington, DC: National Academy Press, 1990.

19. John WG, Webb AM, Jones AE. Glycosylated haemoglobin and glycosylated albumin in non-diabetic and diabetic mothers, and their babies. Diabet Med 1985;2:103-4.

20. Malek A, Sager R, Lang AB, Schneider H. Protein transport across the in vitro perfused human placenta. Am J Reprod Immunol 1997;38:263-71.

21. Van den Akker CH, Van Goudoever JB. Recent advances in our understanding of protein and amino acid metabolism in the human fetus. Curr Opin Clin Nutr Metab Care 2010;13:75-80.

22. van den Akker $\mathrm{CH}$, Schierbeek $\mathrm{H}$, Rietveld $\mathrm{T}$, et al. Human fetal albumin synthesis rates during different periods of gestation. Am J Clin Nutr 2008;88:997-1003.

23. Napartivaumnuay N, Niramitmahapanya S, Deerochanawong C, Suthornthepavarakul T, Sarinnapakorn V, Jaruyawongs P. Maternal 25 hydroxyvitamin D level and its correlation in Thai gestational diabetes patients. J Med Assoc Thai 2013;96:Suppl 3:S69-76.

24. Al-Daghri NM, Al-Attas OS, Alokail MS, et al. Lower vitamin D status is more common among Saudi adults with diabetes mellitus type 1 than in non-diabetics. BMC Public Health 2014;14:153.
25. Strobel F, Reusch J, Penna-Martinez M, et al. Effect of a randomised controlled vitamin $\mathrm{D}$ trial on insulin resistance and glucose metabolism in patients with type 2 diabetes mellitus. Horm Metab Res 2014;46:54-8.

26. Poel YH, Hummel P, Lips P, Stam F, van der Ploeg T, Simsek S. Vitamin $\mathrm{D}$ and gestational diabetes: a systematic review and meta-analysis. Eur J Intern Med 2012;23:465-9.

27. Farahati J, Nagarajah J, Gilman E, et al. Ethnicity, clothing style, and body mass index are significant predictors of vitamin D insufficiency in Germany. Endocr Pract 2015;21:122-7.

28. Drucker DJ, Nauck MA. The incretin system: glucagon-like peptide-1 receptor agonists and dipeptidyl peptidase- 4 inhibitors in type 2 diabetes. Lancet 2006;368:1696-705.

29. Hiles RA, Bawdon RE, Petrella EM. Ex vivo human placental transfer of the peptides pramlintide and exenatide (synthetic exendin-4). Hum Exp Toxicol 2003;22:623-8.

30. Adrian TE, Soltesz G, MacKenzie IZ, Bloom SR, Aynsley-Green A. Gastrointestinal and pancreatic hormones in the human fetus and mother at 18-21 weeks of gestation. Biol Neonate 1995;67:47-53.

31. Anini Y, Hansotia T, Brubaker PL. Muscarinic receptors control postprandial release of glucagon-like peptide-1: in vivo and in vitro studies in rats. Endocrinology 2002;143:2420-6.

32. Jackson Huang TH, Brubaker PL. Synthesis and secretion of glucagon-like peptide-1 by fetal rat intestinal cells in culture. Endocrine 1995;3:499-503.

33. Otonkoski T, Hayek A. Constitution of a biphasic insulin response to glucose in human fetal pancreatic beta-cells with glucagon-like peptide 1 . J Clin Endocrinol Metab 1995;80:3779-83.

34. Biancotto A, Feng X, Langweiler M, Young NS, McCoy JP. Effect of anticoagulants on multiplexed measurement of cytokine/chemokines in healthy subjects. Cytokine 2012;60:438-46.

35. Al-Aissa Z, Rosta K, Hadarits O, et al. Cord serum dipeptidyl-peptidase 4 activity in gestational diabetes. Eur J Clin Invest 2015;45:196-203.

36. Kuhre RE, Wewer Albrechtsen NJ, Hartmann B, Deacon CF, Holst JJ. Measurement of the incretin hormones: glucagon-like peptide- 1 and glucosedependent insulinotropic peptide. J Diabetes Complications 2015;29: 445-50.

37. Hollis BW, Kamerud JQ, Selvaag SR, Lorenz JD, Napoli JL. Determination of vitamin D status by radioimmunoassay with an 125I-labeled tracer. Clin Chem 1993;39:529-33.

38. Rosen CJ, Gallagher JC. The 2011 IOM report on vitamin D and calcium requirements for north America: clinical implications for providers treating patients with low bone mineral density. J Clin Densitom 2011;14: 79-84.

39. Dawson-Hughes B. Serum 25-hydroxyvitamin D and functional outcomes in the elderly. Am J Clin Nutr 2008;88:537S-40S.

40. Kouzuma T, Usami T, Yamakoshi M, Takahashi M, Imamura S. An enzymatic method for the measurement of glycated albumin in biological samples. Clin Chim Acta 2002;324:61-71. 